Courrier du Centre international Blaise Pascal

$2 \mid 1980$

Varia

\title{
Éphéméride et actes de naissance
}

\section{Marie-Thérèse Sart}

\section{OpenEdition}

\section{Journals}

Édition électronique

URL : http://journals.openedition.org/ccibp/389

DOI : $10.4000 /$ ccibp.389

ISSN : 2493-7460

\section{Éditeur}

Centre international Blaise Pascal

\section{Édition imprimée}

Date de publication : 4 janvier 1980

Pagination : 1

ISSN : 0249-6674

\section{Référence électronique}

Marie-Thérèse Sart, "Éphéméride et actes de naissance », Courrier du Centre international Blaise Pascal [En ligne], 2 | 1980, mis en ligne le 23 novembre 2015, consulté le 23 avril 2019. URL : http:// journals.openedition.org/ccibp/389 ; DOI : 10.4000/ccibp.389

Ce document a été généré automatiquement le 23 avril 2019.

Centre international Blaise Pascal 


\title{
Éphéméride et actes de naissance
}

\author{
Marie-Thérèse Sart
}

1 Le 4 juillet 1980 le Conseil de l'Université Clermont II votait un projet de Convention entre la Ville et l'Université créant le Centre International Blaise Pascal au sein de la Bibliothèque Municipale et Interuniversitaire.

2 Le 28 octobre 1980, à l'occasion de la réception à l'Hôtel de Ville d'un groupe de lycéens suisses, venus travailler à la Bibliothèque sur Blaise Pascal, Monsieur le Sénateur-Maire Roger QUILLIOT, et Monsieur Pierre Cabanes, Président de l'Université Clermont II, mettaient la dernière main à cette convention, et ils y apposaient leurs signatures à la date du 23 novembre 1980. Cette convention constitue l'acte de naissance officiel du Centre.

3 Grâce à nos amis suisses la gaîté et la jeunesse entouraient ce nouveau-né à qui sont promis en héritage le riche patrimoine documentaire de la Bibliothèque Municipale et le potentiel intellectuel de l'Université.

4 Le vendredi 5 décembre une réunion plus austère, le premier conseil d'administration, réunissait à la Mairie ceux qui avaient œuvré pour la création du CIBP et parmi eux MM. Jean Mesnard et Philippe Sellier.

5 Au cours de ce conseil, étaient désignés, un directeur scientifique: Madame Thérèse Goyet, professeur à l'Université Clermont II et spécialiste du $17^{\text {ème }}$ siècle, et un directeur scientifique adjoint: Monsieur Dominique Descotes, assistant à l'Université Clermont II, qui prépare une thèse sur Pascal. Monsieur le Maire annonçait en outre le recrutement à mi-temps d'une personne pour le travail du Centre, à partir de janvier 1981.

6 Au cours de ce même conseil était également décidée la création d'une association Amis et Correspondants $d u$ CIBP. Cette association aura pour tâche de soutenir le jeune CIBP dans ses premiers pas, de fédérer les bonnes volontés autour de lui et d'établir entre tous les pascalisants les liens nécessaires à une active coopération.

7 Depuis novembre 1980, grâce à une aide du Ministère des Universités une jeune femme titulaire d'une maitrise de Lettres, Madame Caroline Durand, a commencé, sous la direction de Madame Goyet et de Mademoiselle Seguin, Conservateur à la BMIU, à 
constituer le fichier du CIBP en recensant les fonds de la Bibliothèque Municipale et Interuniversitaire intéressant Pascal. Elle continuera ce travail sur le poste à mi-temps créé par la Mairie et passera ensuite aux autres collections conservées dans la Région.

Du 9 au 11 octobre 1981, le CIBP aura l'honneur et le plaisir de recevoir les Amis de PortRoyal, pour un colloque consacré à Deux grandes figures d'Auvergne: Gilberte et Jacqueline Pascal. À cette occasion s'ouvrira une exposition sur le thème : Blaise Pascal «auvergnat »: la famille à l'ceuvre, qui sera installée - nous l'espérons - avec le concours du Ministère de la Culture et de la Communication, dans l'hôtel de l'intendant Chazerat, 2, rue Pascal. Et de cette exposition pourra naitre un « musée Pascal » permanent, compensation à la maison natale disparue.

Vous trouverez dans ce Courrier $n^{\circ} 2$ les statuts qui fondent le Centre et ceux de l'association de soutien, ainsi que la composition du bureau provisoire de celle-ci. Nous les recommandons à votre attention qui ne peut être que bienveillante et efficace. N'égarez pas non plus la petite notice sur l'association que nous insérons en feuille volante, avec un bulletin d'adhésion, mais faites-en le meilleur usage par vous-même ou en le remettant à vos amis pascalisants ou sympathisants. Vous pouvez même en tirer des photocopies pour diffusion si cela se révèle pratique dans le pays où vous vous trouvez. Car le CIBP est, et sera, votre création.

10 Les adhésions prennent un bon départ et nous avons déjà reçu, des membres d'honneur sollicités, des réponses chaleureuses qui nous donnent à penser que notre projet dans son ensemble répond à l'attente fervente des lecteurs et amis de Pascal lui-même.

11 Nous espérons donc vous retrouver avec le $\mathrm{n}^{\circ} 3 \mathrm{du}$ Courrier, qui portera la date (que nous voudrions réelle) de 1981, et qui vous apportera d'autres bonnes nouvelles.

\section{AUTEUR}

\section{MARIE-THÉRÈSE SART}

Conservateur en Chef de la Bibliothèque Municipale et Interuniversitaire 